\title{
Biliteracy: A Systematic Literature Review about Strategies to Teach and Learn Two Languages
}

\author{
John J. Ducuara \\ Universidad de la Sabana/Centro de Tecnologías para la Academia, Bogotá, Colombia \\ Hugo A. Rozo \\ Universidad de la Sabana/Centro de Tecnologías para la Academia, Bogotá, Colombia
}

\begin{abstract}
This article describes the qualitative research findings with the objective of identifying the strategies implemented in the different educational levels (preschool, primary, high school, and, higher education) in order to develop biliteracy. A systematic literature review was carried out, by means of a search strategy rigorously defined. It aims to describe and evaluate the strategies used. The sample consisted of 122 publications, produced between 2007 and 2017. The results obtained allowed to identify the advances in terms of strategies regarding biliteracy in preschool, primary, high school and university, also it showed that some strategies are used in more than one educational level. Besides, some proposals are mentioned, to modify the institution curriculum. In addition, some advantages and disadvantages are established regarding the implementation of the strategies used to work on biliteracy in the target levels. Based on this, the state of the subject is discussed, and a projection is also generated regarding the needs of the field.
\end{abstract}

Index Terms - biliteracy, language learning strategies, language teaching strategies

\section{INTRODUCTION}

To start the present article and to make it easier to readers, it makes necessary to establish what biliteracy means. To do that, it was indispensable to sum up the definitions that are presented in some articles from the review. Biliteracy is the combination of literacy and bilingualism, and it is used to refer to both bilingual and multilingual literacy (Gentil, 2011; Hornberger \& Link, 2012) and from a sociocultural perspective, biliteracy occurs for some people who obtain literate abilities in two languages at the same time (Hu \& Commeyras, 2008; Babino, 2017). However, some authors are more specific, and they refer to written language development in two languages, either simultaneously or successively (Ro \& Cheatham, 2009; Smith \& Murillo, 2013; Fránquiz, Leija, \& Garza, 2015). Nevertheless, others conceptualize it as being a proficient reader in both languages (Rauch, Naumann, \& Jude, 2012). In contrast, there are some researchers who combine both, writing and reading, they perceive biliteracy as the capacity of the effective use of the language to decipher texts, it means, being able to read and write in wider contexts (Crhová \& Domínguez, 2016).

Biliteracy is developed in several contexts and through social interaction. It can be seen as a process that involves the interlacing of two languages in an active and constant way, mixing skills development, knowledge construction, and experiences (Musanti, 2015). On the other hand, some researchers consider biliteracy as a process to develop concepts and expertise for thinking, listening, speaking, reading, and writing in two languages, making relevant cultural and linguistic connections with printed material and learners' experiences, manipulating the two linguistic writing systems to make meaning (Reyes, 2012; Rubinstein-Ávila, Sox, Kaplan, \& McGraw, 2015).

Based on the previous definition, for this article, biliteracy will be understood as being literate in two languages, making possible to transfer skills from one language to another in order to be able to read, write, and speak in both languages and to adapt to different situations and contexts.

As it is shown in Fig. 1, biliteracy research has been worked since 1982, however, since that date and taking as reference Scopus database, only 291 documents have been published regarding the subject until today, 2017. In addition, the study of biliteracy has become more significant for the last ten years, because of the increase visibility of diverse communities where people are growing up bilingual and, in some cases, biliterate. In addition, research seeks to improve the learning and teaching experiences of different educational levels and from diverse linguistic backgrounds. 


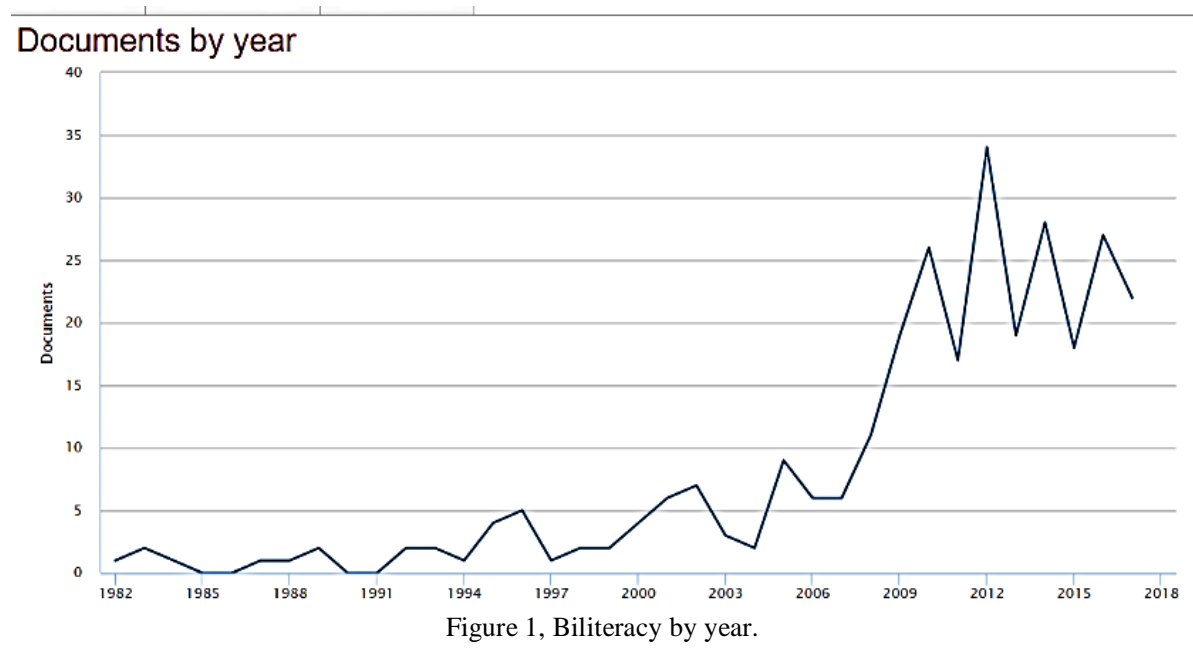

In fact, from Scopus, it is possible to establish where the focus of the investigation is. United States occupies the first place in this matter; it has produced 177 out of the 291 documents, followed by Canada with 22 documents; making evident the distance among countries in the research field and the topic. Also, it is possible to assume that this amount of articles about biliteracy respond to a necessity to instruct immigrants, since they represent a significant quantity of population in the United States, and perhaps institutions have given them an important role since they are interested in making them literate in the local language.

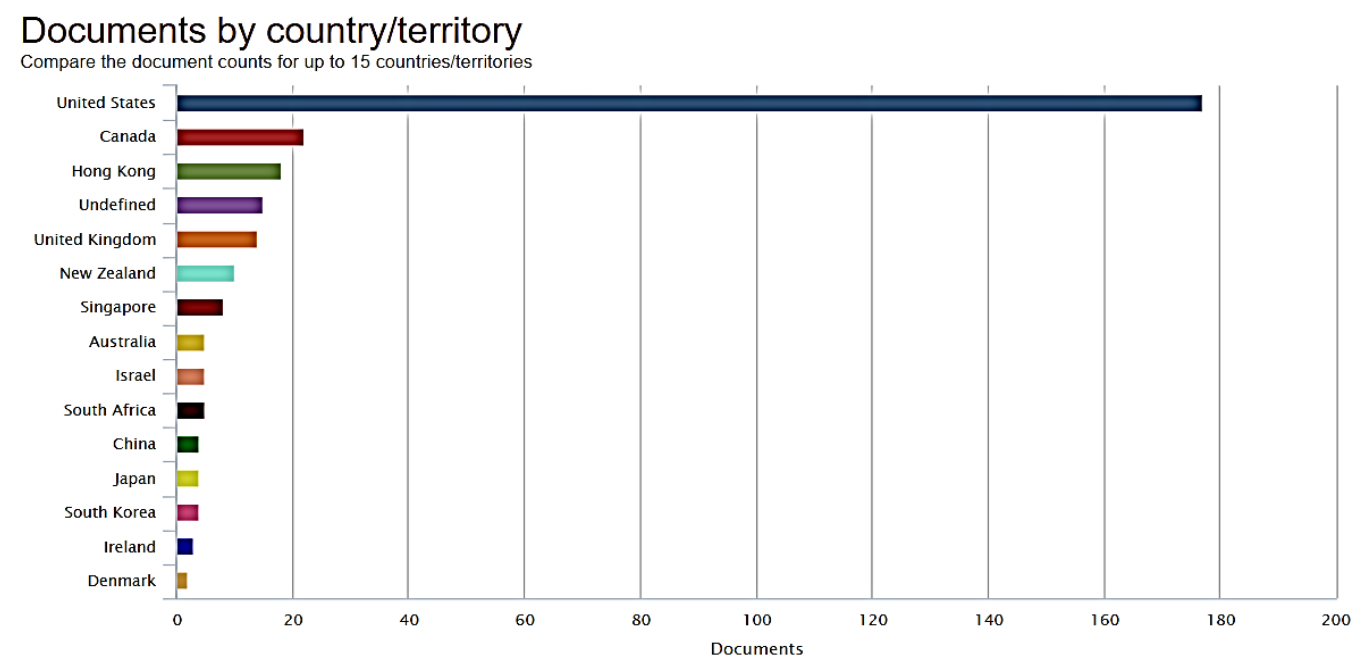

Figure 2. biliteracy by country

Furthermore, it becomes relevant to know about the practices applied in different educational scenarios, due to this, the general objective is: To identify the strategies used to carry out the development of biliteracy and to determine the effectiveness of those strategies in the instruction in two languages in educational and non-educational contexts.

\section{METHOD}

\section{A. Type of Study}

The present study is a research literature review, which is defined as a systematic, explicit and reproducible method to identify, evaluate and synthesize the existing body of work done and registered by researchers, academics and professionals (Fink, 2005). The types of literature review used in this article are descriptive and interpretative, since the descriptive review provides the reader with an update of useful concepts in areas in constant evolution, and the interpretation review responds to a very specific question about the issue (Day, 2005; Cué, Díaz, Díaz \& Valdés, 2008).

\section{B. Sample}

The sample initially consisted on 122 publications or units of analysis and then it became into 61 articles, which come from 3 databases, (Scopus, Web of Science and Taylor \& Francis) and whose inclusion and synthesis was given from the process that is described in Figure 1. They were taken into account publications made between 2007 and 2017 (August). 
First, the term Biliteracy was used as the key word to do the searching, it was used in three databases (Scopus, Taylor and Francis, and Web of Science), also the criteria applied depended on the database as it is established in Figure 3, each databank came up with certain number of articles. After this, an Excel chart was created to identify if there were any documents repeated among the three databases. When this process was done, there were 64 documents in total, but unfortunately 3 articles were not possible to find. As a result, 61 articles compounded the sample of this review, those 61 documents were deeply read and analyzed.

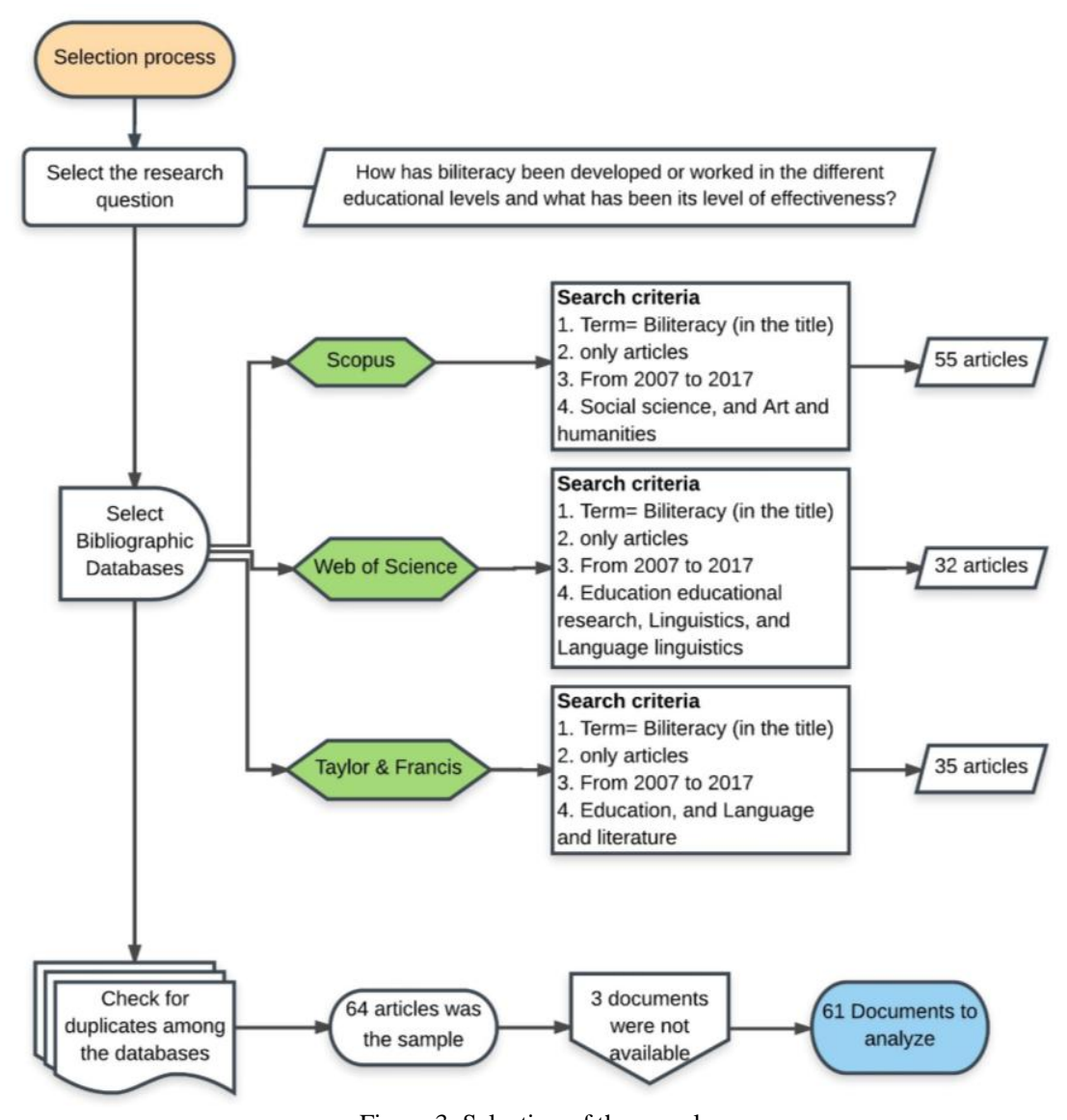

Figure 3. Selection of the sample.

\section{Document Analyses}

So as to be systematic with the literature review of the documents, it was necessary to use a software used to code qualitative data, called Atlas.ti. It was used to upload the 61 articles found. Then each article was completely read and coded. Considering codes previously created, (See Fig. 4) each code was considered a category and most of them were a priori (Miles \& Huberman, 1994). However, there was one category that came up while doing the reading: curriculum, which was an emergent category for the review. The frequency of the curriculum category was low, but for the review it was considered relevant. Besides, the category teacher role was used as part of the conclusions of the document since the frequency of this matter was not high.

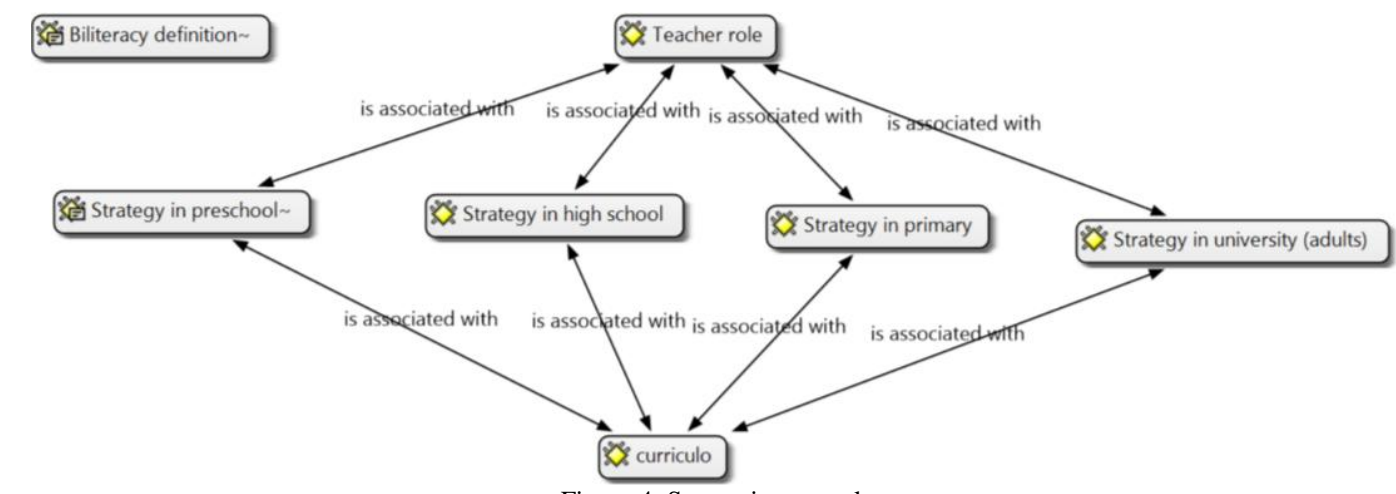

Figure 4. Semantic network 


\section{RESULTS}

As it was mentioned in the method, the 61 documents were coded to classify them to have the necessary information about the strategies used to work on biliteracy. The results are presented in categories, also, as it was stated before, the teacher role is presented with the conclusions and the Biliteracy definition was mentioned during the introduction of the document, since they are considered as transversal aspects. Furthermore, some commonalities were established between strategies and educational levels, these findings will be discussed later. The next Fig. 5 shows the frequency in which each category was used during the analysis.

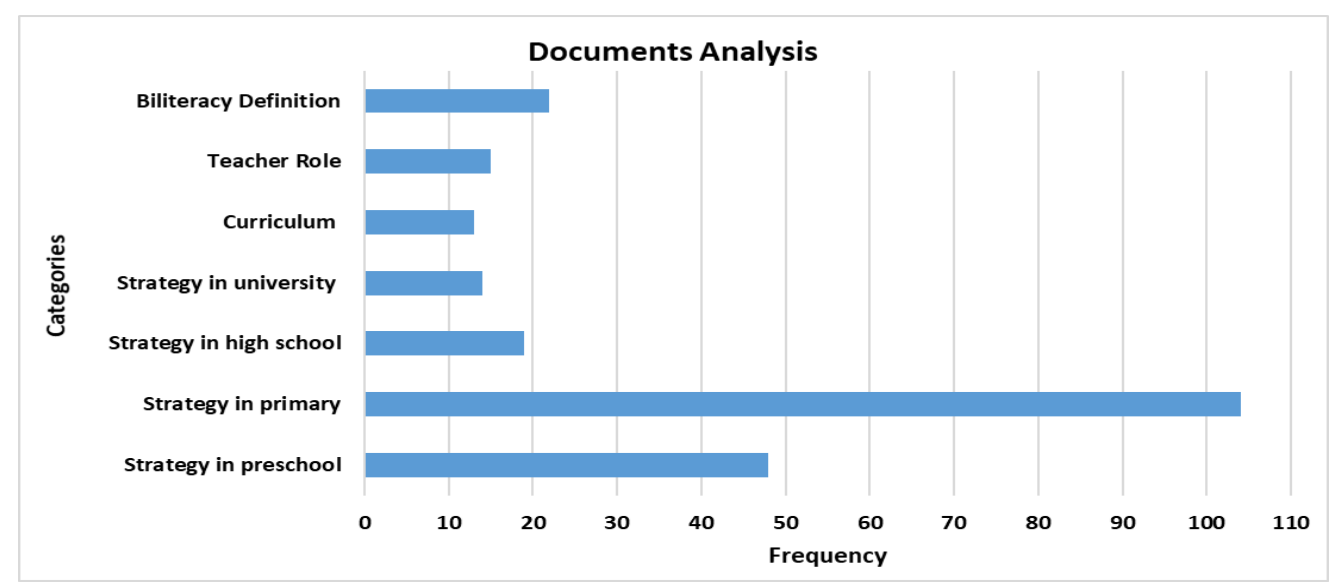

Figure 5, Documents Analysis

\section{A. Strategies in Preschool}

The following section provides an overview of the nine strategies storytelling, SEAL (Sobrato Early Academic Literacy), discourse strategies, receptive vocabulary/grammar, phonological awareness, whole word strategy, home literacy, code-switching, and environmental print awareness) found across the analysis of the documents. The code frequency was 48 among the 61 documents as it is shown in figure 5. While the analysis was carried out, it was taken into account the population and any kind of activity involved to biliteracy development.

1. Storytelling

It is the art of telling a story. The creation and enjoyment of a magical atmosphere through the story. It has been used to develop a variety of skills when learning a language. For that reason, it is one of the most common strategies used in developing biliteracy among kids. Storytelling can be used with picture books for labeling, sentence making, and work on invented spelling (Hu \& Commeyras, 2008). Also in some cases, it is necessary to work on one-on-one assistance as the kids need it to guarantee the comprehension of the story (Huerta, 2010; Lucero, 2010). However, it is necessary to explain children the function of books, to let them go beyond the reading, they can be able to understand and differentiate whether a book was written in Spanish or English or the language instructed. Most of the children demonstrated knowledge that the printed material carried messages, they were able to point directly to the title of the book and indicate where the beginning and end of the text was (Reyes \& Azuara, 2008). Moreover, they focused on the images that illustrated the book, helping understanding and presenting that they are enough to comprehend a story. In fact, stories served as a challenge to counter presuppositions, perceived wisdoms, and assumptions of the dominant discourse among students (Boutte \& Johnson, 2013b).

2. SEAL (Sobrato Early Academic Literacy)

It is a model created for Spanish-speaking kids, who are in kindergarten and do not know English or just a little; they are called English Language Learners (Lindholm-Leary, 2014).

3. Discourse strategies

These strategies are signals used by children to interact in the classroom with teacher and classmates. The strategies are; translation, paraphrasing, and paralinguistic signals (Reyes et al., 2012).

4. Receptive vocabulary/grammar

When talking about vocabulary, it means, that the student has to choose among some drawings the one that best matches the word spoken by the adult; regarding grammar, the strategy is similar to vocabulary. In this case, the student must select the image that best matches the sentence spoken (Jared, Cormier, Levy, \& Wade-Woolley, 2011).

5. Phonological Awareness

Several studies work on the development of phonological awareness in order to favor the biliteracy development. Phonological awareness has been repeatedly reported as a key strategy for learning to read different orthographies, it is carried out through different activities, such as, word decoding in each language, rime analogy, grapheme-phoneme recoding strategy and word cards, in order to enhance the print knowledge awareness in one language to support the development in the other (Kang, 2012). Also, it can be developed through syllable and phoneme deletion and phoneme isolation with the intention to create awareness about the sounds of the phonemes. In various studies. Infants had to 
erase five opening and ending syllables from words compound by two syllables. Then, they listened and said a complete word and repeated the word again but deprived of saying the deleted syllable or phoneme (Jared, Cormier, Levy, \& Wade-Woolley, 2011; Burgoyne, Duff, Nielsen, Ulicheva, \& Snowling, 2016). Thus, English rhyme detection to support the phonological awareness consisted of two practice items. Infants must select from a list of words, a suitable one that rhymed with the given word. In addition, it is important to understand what specific levels of phonological awareness are involved in learning a second language. They are, word reading, letter name knowledge, receptive vocabulary, and non-verbal intelligence, and they contribute in the different linguistic units including syllable, rhyme, phoneme, and tone awareness (Yeung \& Ganotice, 2014).

6. Whole word strategy

It promotes that pupils understand and recognize words as a complete unit that carries meaning that it is not necessary to divide into smaller particles. This strategy comprehends the word as the backbone of the reading. In this strategy Russian/English reading focus on sight words to learn them and create meaning from them (Toloa, McNaughton, \& Lai, 2009; Burgoyne et al., 2016)

7. Home literacy

Researchers have tried to involve families into the (bi) literacy process. The school asked parents to share the literacy material from their native language in order to use them as developing material for reading and writing to motivate students and show the relationship between school and home literacy practices (Reyes et al., 2012). In the same way, parents and relatives has to work with children, in order to show that their linguistic knowledge was an asset for their children's biliterate education. Parents needed the guidance from the teachers, they required to be trained in strategies to support their kids biliteracy development (Delbridge \& Helman, 2016), for instance, In Rodriguez' study, findings report the usage of a sequence: "1) validating the linguistic knowledge migrant parents had in Spanish, 2) introducing how to transfer reading skills from one language to another, 3) developing phonemic awareness in both languages, and, most important, 4) introducing cooperative biliteracy learning practices for parents and students" (2014. p 113).

8. Code-switching

Certain biliteracy-related processes support dual-language reading and writing competencies in children. Such process is code-switching, now widely studied in the literature across ages and groups. Infants who have the opportunity of inferring and understanding from several languages can achieve their conversational and communicative needs; different from monolingual children.

Reyes et al., speakers benefit from code-switching and mutual exchanges in their language usage, since they are capable of intercalate between languages, but in the case of preschool the code-switching comes from the adults, specially teachers, which it can be seen in two ways; first, as adaptation, where children are likely to learn to code switch and alternate between languages depending on the context and benefits (2012). Second, improvisation which refers to, a code meshing or code mixing, it means, blending the two languages in their speech and writing (Boutte \& Johnson, 2013b).

9. Environmental print awareness

Working with environmental products in preschool are essential for developing a language. These items are usually tagged in different languages and can be used as a strategy, called environmental print. It offers the kids experiences with other languages and its usage depends on the person and the position. That is why; people should get as much as possible environmental print material at school. Children realize about the print material around them and they start to interact with it, since they identify and read common words from their surroundings (Reyes \& Azuara, 2008).

\section{B. Strategies in Primary}

The following section provides an overview of the fourteen strategies (Phonological awareness, Code-switching, Home Literacy, Storytelling, Vocabulary acquisition, Reading aloud, Spontaneous writing, The paired literacy model, Literacy Squared model, Cognates, Pre-service and in service teachers, Morphological awareness, Deletion, Collaborative writing) found across the analysis of the documents, the code frequency was 104 among the 61 documents as it was shown in Fig 5.

1. Phonological awareness

Phonological awareness appears once more time, as in preschool. Children are older, and they are capable of more challenging activities, first, syllabic and phonemic awareness are worked by using flashcards to assess the ability to recognize the sounds of words and pseudowords by naming each one of them. Likewise, letter-name and letter-sound knowledge can be shown through 26 cards that had a letter of the alphabet printed in uppercase letters (Wang, Yang, \& Cheng, 2009; Jared et al., 2011). Second, decoding skills are worked and developed in this kind of population through oral language and reading tasks, (Nakamura, Koda, \& Joshi, 2014; Giambo \& Szecsi, 2015). These authors state that phonological awareness facilitates to enhance the decoding skills through metalinguistic abilities to manipulate speech sounds, independent from their meanings across languages, it would mean that reading comprehension would be aided (Toloa, McNaughton, \& Lai, 2009; Chung, Mcbride-Chang, Cheung, \& Wong, 2013). Phonological awareness can be worked from auditory discrimination too, in which the teacher says out loud a pair of monosyllabic words (e.g., /web/ and /wed/) and participants were to judge whether they were the same or different words and the phonemic contrast is located in word-initial, -medial, and -final positions (Reddy \& Koda, 2013).

2. Code-switching 
Sympathy to sociocultural prospects and standards in certain backgrounds are permitted by code switching, for instance when bilinguals display their linguistic collections in the two languages (Ro \& Cheatham, 2009; Boutte \& Johnson, 2013), students use both languages to make sense of assignments, and as normal practice with little awareness of linguistic shifts; at other times, students purposely shift languages to show their biliteracy competence (Reyes, 2012; Hornberger \& Link, 2012).

3. Home Literacy

Parents can provide an environment to promote biliteracy. The interaction between parents and children are crucial to the learning process of literacy skills. Furthermore, Parents can continue the literacy activities started at school in order to motivate their kids to read write and speak (Ro \& Cheatham, 2009). When parents are constantly reading at home, they can share the reading time with children, even when they read newspapers or online journals. They can share the reading when they are reading any material from their own interests (Obied, 2010).

4. Storytelling

Children appreciate the stories in their home or foreign language; besides, bilinguals are most of the time enquiring and comparing the languages (Ro \& Cheatham, 2009; Medina et al., 2010). It is necessary to assess the kinds of words students use in their retelling and how students use words to make sentences, to be aware of the acquisition for the two languages (Toloa et al., 2009). Moreover, one has to distinguish between storytelling occurring in everyday conversation and schooled narratives, which are more closely associated with literacy practices (Hornberger \& Link, 2012b; Bongartz \& Torregrossa, 2017).

5. Vocabulary acquisition

It is acquired through guided reading, using explicit forms such as elaborations and incidental instruction, like repeating models in contexts, identifying emotive words from a series of sentences and reading different genres or styles of writing (Toloa et al., 2009). Furthermore, it can be acquired through naming objects from pictures, reading isolated words; there are cloze activities, in which kids have to complete short texts choosing a word to complete a passage. It can be done orally or written (Proctor \& Silverman, 2011; Jared et al., 2011).

6. Reading aloud

It is a simple activity, and it does not take too much time to carry out. However, is worthy and so beneficial to develop a range of skills to support the biliteracy development, this kind of reading comes from parents, teachers and students themselves. Furthermore, it is not as important as people could think the kind of material, they can be tales, poetry, and any reading material (Menard-Warwick, 2007; Giambo \& Szecsi, 2015). Through reading, it is possible to discover that words are used differently in different contexts or domains and that there is not always one correct linguistic answer (Obied, 2010). Also, it is necessary to make questions to guarantee the understanding of the reading, making sure the use of the two languages (Huerta, 2010; Fránquiz \& Ortiz, 2012).

7. Spontaneous writing

It is the creation for short and easy written pieces of text, such as, letter to a relative, narrating daily events and using simple tenses in their productions (Menard-Warwick, 2007). Besides, it is crucial to contrast the written productions, modeling is not enough to acquire the necessary skills in a second language. Teachers must make a parallel of the rules, contrast them and show infants who are emerging literacy in to two or more languages (Boutte \& Johnson, 2013).

8. The paired literacy model

This model is based on the instruction of the two languages simultaneously, the second language is taught while the kids are learning to read and write in the native language. It is different from other models that establish a limit among languages to separate them. This model states that both languages can co-develop. However, in this proposal, to start the instruction in the second language, it is necessary to have certain proficiency level in the foreign language (SolteroGonzález et al., 2016).

9. Literacy Squared model

This model nurtures literacy skills in two languages and highlights teaching approaches and the usage of different kinds of texts. Among the approaches it can be found, modeled, shared, collaborative, and independent writing and reading. To work on the oral skills, it is necessary to provide meaningful opportunities to interact and learn the use of vocabulary and language structures (Soltero-González et al., 2016).

10. Cognates

Cognate is a word that comes from the same origin as a word from a different language. Cognates between languages usually have similarities in spelling, pronunciation, and meaning. Reading performance is enhanced for bilinguals who recognize cognates, and add that the ability to infer the meaning of words by using internal context, morphology, and knowledge of multiple meanings also supported bilingual reading (Soto, 2012; Giambo \& Szecsi, 2015).

11. Pre-service and in service teachers

To recruit pre-service and in-service teachers from similar ethnic backgrounds of students was a strategy used by Brochin (2012) in order to make more comfortable and gain confidence to children. In that way, they can be more productive and efficient in the tasks.

12. Morphological awareness

It refers to the capacity to use morphemes and morphological structures. When it is coming from youths' morphological awareness, it reflects in the morphological structure of the home language. Since, it involves breakdown 
and management abilities. Also, a well-documented quantity of research has stated the relevance of the development of word-reading skills where readers can make direct letter-sound correspondences (Wang, Ko, \& Choi, 2009; Zhang, Koda, \& Sun, 2014; Zhang, 2016; Bae \& Joshi, 2017).

13. Deletion

In English, students are asked to delete syllables or phonemes from words that are said out loud by the adults. For instance, the child has to say /batman/ without /bat/ (syllable-level deletion), or say /bat/ without /b/ (phoneme-level deletion) (Wang, Yang, \& Cheng, 2009; Wang, Ko, \& Choi, 2009; Reddy \& Koda, 2013; Lü, 2017).

14. Collaborative writing

In some classrooms, there are students who are not bilingual, which is not a limitation when writing, pairs of the same-language can get involved in the writing process. Papers can be written in their native language, after, translated into the second language with the help of their classmates and then shared with the complete group (Hornberger \& Link, 2012; Delbridge \& Helman, 2016). Gort proposes a writing workshop that lasts from 45-60 minutes, first the language to write is chosen, second, students read aloud and third, comments are made by students and finally the written production is improved based on the comments (2008).

\section{Strategies in High School}

The following section provides an overview of the nine strategies (genre writing, morphological relation, reading and writing for pleasure, home literacies, translation, chalk talks, morphological awareness, writing sequence, and social networks) found across the analysis of the documents, the code frequency was 19 among the 61 documents as it was shown in figure 5. While the analysis was carried out, they were taken into account the different grades included in high school and the activities that foster biliteracy growth.

1. Genre writing

It mixes the understandings from literacy and bilingualism to enrich polyglot authors to cultivate and practice genre proficiency in different languages (Gentil, 2011). It is based on promoting writing by using any genre known by students.

2. Morphological relation

It teaches students to relate and be conscious about where words come from, for instance, teach-teacher, students have to make pairs in order to identify the relationship between them. And get to know the affixes and how words are change depending on them, unhappy-happy (Zhang \& Koda, 2014).

3. Reading and writing for pleasure

It is necessary to promote the free reading and writing production, it is not necessary to link them to an academic task. Teens can read any kind of material, such as, comics, baseball novels, surfing on the internet, historical and action books. Furthermore, they can practice writing through mailing friends (Haneda \& Monobe, 2009).

4. Home literacies

Model reading at home is crucial and it does not matter the age, it is extremely important that parents show kids that they read too. It could be books, newspapers, children's books. In addition to this it is necessary to share activities as watch TV or listening to the radio and playing computer games (Obied, 2010).

5. Translation

A bilingual representation is the product of translation. It is a process that involves selecting from the target language the necessary corresponding counterparts of the second language in the context of the source text. When translating for practical purposes, the overriding objective is to endow the target text with the same communicative effect as that of the source text (Ngan, 2009).

6. Chalk talks

It is an activity where a long piece of paper is used with a question written on it. Students can answer the question orally or written on the paper. Students can also make extra questions to the teacher and their classmates in their home language or the foreign language, both are acceptable in this strategy (Rubinstein-Ávila et al., 2015).

7. Morphological awareness

It refers to the capability to recognize, examine and use the language units. In addition, it can promote students' comprehension skills. Research results have indicated that metalinguistic awareness on orthographic and phonological parts are important skills for early literacy development in different languages (Bae \& Joshi, 2017).

8. Writing sequence

In academic writing it is advisable to follow some steps to guarantee a high quality written production, the steps are: prewriting, drafting, proofreading, revising, and publication ( $\mathrm{Pu}, 2010)$.

9. Social networks

They can be used to foster writing and to connect with people whit mother tongue or the second language that students want to learn (Hornberger, 2007; Worthy, Nuñez, \& Espinoza, 2016).

\section{Strategies in Higher Education}

The following section provides an overview of the five strategies (Narratives, Bilingual dictionaries, Genre theory, Projects, Code-switching) found across the analysis of the documents, the code frequency was 14 among the 61 
documents as it shows figure 5. While the analysis was carried out, it was take into account any reference to higher education.

\section{Narratives}

This strategy is done when stories are written by students, telling their own life experiences, regarding their literacy process. Narratives allow teachers know students understanding and interpretation within some specific contexts, making them improve their own writing quality (Cho, 2010).

2. Bilingual dictionaries

They are used to comprehend the meaning of demanding vocabulary, helping users with web pages or thesaurus (Walt \& Dornbrack, 2011).

3. Genre theory

It uses the genre knowledge and meta-knowledge in the first language as a resource for navigating academic writing tasks in second language. Two concepts from genre studies have particular resonance: the notions of genre repertoire and genre competence. Looking at genres as not only socially situated, but also as interconnected is critically important, and the concept of genre repertoire draws attention to precisely these connections (Mein, 2012).

4. Projects

Class projects can be used as the channel to foster the development of multiple skills, since they have to write, read and interact with mates, which implies listening and speaking, for instance a book project telling a variety of experiences like a biography (Hornberger, 2007; Hornberger \& Link, 2012b; Crhová \& Domínguez, 2016).

5. Code-switching

This strategy is used in every single educational level, as it is defined as an oscillation of two languages within a single discourse, but it can be seen as a problem from monolingual mindset (Crhová \& Domínguez, 2016). Codeswitching could be considered as a tool in learning ability development as it helps students' knowledge grow. In research, it has been classified as code-mixing, code-switching, and translanguaging (Kwon \& Schallert, 2016).

Based on the previous information some common strategies were found among the educational levels, codeswitching and home literacy appeared in 3 out of 4 levels, first, code-switching, it works as evidence of the importance that this strategy has during the whole process of getting a second language, this can be used as a transition and to show some similarities between languages, making easier for learners the acquisition of a foreign language. Second, home literacy, the information found states the relevance and how significant the learner's family is in the learning process, family members are crucial to improve students' skills, it is not necessary to have planned activities to develop as a family, their daily life and experiences are a font of significant input to students if they are well supported and company the person.

On the other hand, storytelling, phonological awareness, and morphological awareness appeared in 2 of educational levels. First, storytelling shows the relevance to work with it in preschool and primary, it develops students' skills for reading but also; it improves their vocabulary and their speaking skills, since; they are able to tell their own stories; they learn about the sequence of a write-up and apply it not just to tell something, they learn o plan their own activities in order to follow a sequence. and last, storytelling in those ages motivate students to read and stimulate their imagination, since each story takes them to different worlds. Second, phonological and morphological awareness are crucial in the acquisition of a language, both work from the smallest to the biggest part of a language, and when students are aware of it, it is much easier for them to gain fluency when they talk, write or read. If they can understand how phonological and morphological awareness work, they will be able to comprehend what they learn, making the process meaningful and unforgettable.

\section{E. Curriculum}

There were strategies implemented in some research projects that were not possible to place in a specific educational level, since they affect the whole curriculum. During the analysis of the documents, this code was used 13 times.

There have been some research papers that emphasizes on the necessity to enrich the policies, programs, pedagogies, and practices that lead to biliteracy and cultural pluralism (Rodríguez \& Cadiero-Kaplan, 2008; Evans, 2013). A good example can be seen in Mainland China, where it is mandatory the learning of Pinyin at the beginning of primary school, it makes part of the national curriculum (Lü, 2017). More over it is necessary to include texts that include both languages and enable the family know about it in the curriculum regarding the biliteracy and individuality growth. The idea is to move beyond a monolingual pedagogy and to include family stories and literacies through the writing of dual language books in order to foster the development of students skills (Hill, 2015; Delbridge \& Helman, 2016).

1. Dual language immersion program

This program consists on the instruction of students from any language background and they are instructed solely in their mother language, from preschool to first grade. Then when students get in to fifth grade, the curriculum becomes $70 \%$ for natives and 30\% for foreign. The percentage increased through the time until it got 50/50 (Granados, 2017).

2. Abilities limitation

Curriculum sometimes limits the abilities of bilingual students to develop academic competence in both languages. (Smith \& Murillo, 2013). For institutions, children whom grow up in homes and communities with two or more languages can be a problem, since teachers must design and implement strategies for developing the classes and guarantee their learning. 
This analysis has reviewed empirical research on the strategies used to work on biliteracy. Existing studies have reported both positive and negative aspects of them. In terms of positive effects, findings have suggested a range of specific areas where biliteracy strategies are advantage.

Firstly, it is worthier that the two writing codes are equals, it means, the characters are the same, the phonemes may be different but most of the letters exist in both languages (Kang, 2012), as in English and Spanish. It also helps to transfer skills between the two languages, for instance in preschool, when the two languages are English and Spanish, students realize about similarities for writing and reading, at the beginning students read as they do it in Spanish, it is not correct but they are getting used to read in a second language, and with practice and rehearsal students can differentiated both languages writing rules. Secondly, when languages have similar written systems, there is a correspondence among skills: It corresponds to numerous biliteracy research projects, which say relevant crosslinguistic associations in metalinguistic abilities as in phonological and morphological awareness (Nakamura et al., 2014) also; it is possible to say that even when some skills are equals among languages, it is more difficult to work on a second language if there is a skills development gap in the first language, for instance, if students have complications about phonological awareness in their native language, it will be harder to get a second language. Thirdly, findings offer signs that a battery of English cognitive exams delivered in preschool can predict the reading skills in both languages. The batteries must comprise phonological awareness, grammatical skills, letter-sound and word recognition (Jared et al., 2011). This point of view is hard to carry out, taking into account that literacy in some countries does not appear in preschool curriculums, It is usually thought in a higher level like primary, however, this particular strategy is possible but it will depend on several factors, for instance, the institution context, the ages of the student, the exposure to the language, among others. Fourthly, books should have cultural features in the stories that allow kids to realize about where they belong to in the world, unfortunately, most of the kids stories are fiction and try to leave a moral for them, but, there are few books that show cultural features in their narrations, it should be worthier and easier to show cultures through tales. Fifthly, results propose the transference of skills when getting two similar writing codes. For instance, the phonological transference happens when the phonological unit appears in both languages. Cross-language morphological transference occurred for compound structure awareness. The findings highlight the shared processes among languages, however, in the case of spelling, it is considered as a precise language process (Wang et al., 2009).

In terms of negative effects, it can be said that the writing system sometimes is not as easy to work with. For instance, the letter-sound correspondence it is not as exact as people will expect, for example, the /th/ sound does not exist in some languages, making more difficult to relate the sound with students' background knowledge (Hu \& Commeyras, 2008). Besides, it also makes difficult the decoding process, since students sometimes needs to learn a complete whole set of sounds and characters correspondence (Nakamura et al., 2014). It may be difficult but at the same time it helps students to improve in their own native language, they have to train themselves and to educate their ear to listen carefully and discriminate sounds. Also, when talking about reading material such as books, the selected material must be chosen with special care, since it may not be culturally sensitive and can leave students feeling at best confused and at worst marginalized and offended (Delbridge \& Helman, 2016). As it was mentioned before the amount of material available regarding cultural features is few, it makes more difficult to try to show beliefs, philosophies, politics, etc. from a book, it is sometimes easier to create the material needed, nonetheless, it can be bias, as it is a subjective material created by the teacher.

\section{Conclusions ANd Prospective}

To sum up, the strategies mentioned for the different educational levels do not belong to a specific grade, most of the strategies can be used from preschool to university level. The strategies just need to be adapted to the corresponding level, it is evident since some strategies are common in 2 or 3 educational levels, for instance code switching. However, to carry out those adaptations, it is necessary to have the appropriate group of people to instruct students in the best way. It is not the same to work on phonological awareness in preschool and primary, some features are common, but the methodology used is different, that is the reason to have the necessity to count with proficient people to carry out the task. Teachers assume a crucial role in biliteracy process and development. A teacher to work on biliteracy must fulfil some requirements.

Firstly, teachers should create an environment in which biliteracy development is supported, an environment that makes students feel confident and safe to use both languages, and plan activities that validate and include bilingual and biliterate perspectives and practices (Gort, 2008; Delbridge \& Helman, 2016). Also, teachers must encourage students' oral language, literacy, and cultural knowledge, in that way they can improve their communicative skills, and expand their cultural knowledge.

Secondly, teachers can engage children in multiculturally themed units to link them to different cultures through content and students' own culture and language, to show different backgrounds and the importance to get to know philosophies. To do this, teachers can group and mix students who have or not similar language or cultural surroundings and backing them while they interact in their first language and practice a second one. To do that teachers should learn about bilingual students' background knowledge, cultural repertoires, and daily home practices (Ro \& Cheatham, 2009; Rodriguez-Valls et al., 2014; Fránquiz et al., 2015), if teachers do so, they will be more effective while working with their students, and their progress maybe faster and worthier. 
Thirdly, as a mandatory task teachers should be in charge to provide access to high-quality bilingual books in and out the classroom to promote reading in two languages (Medina et al., 2010; Giambo \& Szecsi, 2015). It can reflect a variety of cultures (Reyes, 2012). It can help kids in many aspects, such as, word recognition, grammar structures recognition, and they can learn about multiple cultures while they read.

Finally, educators must be extremely careful while designing the instruction and plan for interactions that build on translanguaging practices and transnational literacies (Hornberger \& Link, 2012a). Without a well-structured plan, it is not possible to guarantee a biliteracy acquisition process. As there are so many aspects to work on biliteracy, it is necessary to plan in order to not leave behind any factor that contribute to the dual literacy.

On the other hand, there are few articles regarding the biliteracy topic, as it was mention before, there are 291 documents, based on this, it is necessary to keep conducting research in all the educational levels, results indicate that most of the documents are focused on primary, some in preschool but few in secondary and university, it shows the necessity of investigation in those levels, especially when in those levels the amount of bilingual students is high .

Instead, the strategies implemented used printed material, it means they used physical resources, but, it seems that teachers are not using the different tools that ICT can provide to work on biliteracy, some strategies like CALL (Computer-assisted language learning) are used to work on one language, but based on the information provided from the systematic review, there is not enough evidence to say that teacher are really using ICT tools to work and develop biliteracy skills, there are some apps that could support the process for morphological awareness, word recognition, and phonological awareness, among others. It is a field that needs to be more explored and it could provide worthy results.

\section{REFERENCES}

[1] Babino, A. (2017). Same program, distinctive development: Exploring the biliteracy trajectories of two dual language schools. Bilingual Research Journal, 40(2), 169-186. https://doi.org/10.1080/15235882.2017.1307290.

[2] Bae, H. S., \& Joshi, R. M. (2017). Role of morphological awareness in biliteracy development: Within- and cross-language perspectives among Korean ESL learners in grades five and six. Contemporary Educational Psychology, 49, 21-31. https://doi.org/10.1016/j.cedpsych.2016.11.001.

[3] Bongartz, C. M., \& Torregrossa, J. (2017). The effects of balanced biliteracy on Greek-German bilingual children's secondary discourse ability. International Journal of Bilingual Education and Bilingualism, in press (0), 1-16. https://doi.org/10.1080/13670050.2017.1355888.

[4] Boutte, G. S., \& Johnson, G. L. (2013a). Do Educators See and Honor Biliteracy and Bidialectalism in African American Language Speakers? Apprehensions and Reflections of Two Grandparents/Professional Educators. Early Childhood Education Journal, 41(2), 133-141. https://doi.org/10.1007/s10643-012-0538-5.

[5] Boutte, G. S., \& Johnson, G. L. (2013b). Funga Alafia 1: Toward Welcoming, Understanding, and Respecting African American Speakers' Bilingualism and Biliteracy. Equity \& Excellence in Education, 46(3), 300-314. https://doi.org/10.1080/10665684.2013.806850.

[6] Brochin, C. (2012). Literacies at the border: transnationalism and the biliteracy practices of teachers across the US-Mexico border. International Journal of Bilingual Education and Bilingualism, 15(6), 687-703. https://doi.org/10.1080/13670050.2012.699948.

[7] Burgoyne, K., Duff, F. J., Nielsen, D., Ulicheva, A., \& Snowling, M. J. (2016). Bilingualism and Biliteracy in Down Syndrome: Insights From a Case Study. Language Learning, 66(4), 945-971. https://doi.org/10.1111/lang.12179.

[8] Cho, S. (2010). Academic biliteracy challenges: Korean scholars in the United States. Journal of Second Language Writing, 19(2), 82-94. https://doi.org/10.1016/j.jslw.2010.02.002.

[9] Chung, K. K. H., Mcbride-Chang, C., Cheung, H., \& Wong, S. W. L. (2013). General auditory processing, speech perception and phonological awareness skills in Chinese-English biliteracy. Journal of Research in Reading, 36(2), $202-222$. https://doi.org/10.1111/j.1467-9817.2011.01500.x.

[10] Crhová, J., \& Domínguez, M. del R. (2016). Mexican university teacher-researchers' biliteracy beliefs and practices. Journal of Language and Cultural Education, 4(3), 3-31. https://doi.org/10.1515/jolace-2016-0023.

[11] Cué, B., Díaz, G., Díaz, A., \& Valdés, M. (2008). El artículo de revisión. Revista Iberoamericana de Enfermería Comunitaria, 1(6), 1-11. http://ref.scielo.org/sf4xjh.

[12] Day, R. A. (2005). Cómo escribir y publicar trabajos científicos. (Tercera ed, Vol. 0). Organización Panamericana de la Salud.

[13] Reyes, M. (2012). Spontaneous Biliteracy: Examining Latino Students' Untapped Potential. Theory Into Practice, 51(4), 248255. https://doi.org/10.1080/00405841.2012.726052

[14] Delbridge, A., \& Helman, L. A. (2016). Evidence-Based Strategies for Fostering Biliteracy in Any Classroom. Early Childhood Education Journal, 44(4), 307-316. https://doi.org/10.1007/s10643-015-0712-7.

[15] Evans, S. (2013). The Long March to Biliteracy and Trilingualism: Language Policy in Hong Kong Education Since the Handover. Annual Review of Applied Linguistics, 33, 302-324. https://doi.org/10.1017/S0267190513000019.

[16] Fránquiz, M. E., Leija, M. G., \& Garza, I. (2015). "Figuring" Bidirectional Home and School Connections Along the Biliteracy Continuum. Bilingual Research Journal, 38(2), 152-171. https://doi.org/10.1080/15235882.2015.1063552.

[17] Fránquiz, M. E., \& Ortiz, A. A. (2012). Coeditors' Introduction: Home, School, and Program Influences on Bilingualism and Biliteracy. Bilingual Research Journal, 35(November 2014), 253-257. https://doi.org/10.1080/15235882.2012.736846.

[18] Gentil, G. (2011). A biliteracy agenda for genre research. Journal of Second Language Writing, 20(1), 6-23. https://doi.org/10.1016/j.jslw.2010.12.006.

[19] Giambo, D., \& Szecsi, T. (2015). Promoting and maintaining Bilingualism and biliteracy. The Open Communication Journal, 9 , 56-60. 
[20] Gort, M. (2008). "You give me idea!": Collaborative strides toward bilingualism, biliteracy, and cross-cultural understanding in a two-way partial immersion program. Multicultural Perspectives, $10(4), \quad 192-200$. https://doi.org/10.1080/15210960802526086.

[21] Granados, N. R. (2017). Mobilities of Language and Literacy Ideologies: Dual Language Graduates' Bilingualism and Biliteracy. Journal of Literacy Research, 49(2), 210-239. https://doi.org/10.1177/1086296X16686143.

[22] Haneda, M., \& Monobe, G. (2009). Bilingual and biliteracy practices Japanese adolescents living in the United States. Journal of Asian Pacific Communication, 19(1), 7-29. https://doi.org/10.1075/japc.19.1.02han.

[23] Hornberger, N. H. (2007). Biliteracy, transnationalism, multimodality, and identity: Trajectories across time and space. Linguistics and Education, 18(3-4), 325-334. https://doi.org/10.1016/j.linged.2007.10.001.

[24] Hornberger, N. H., \& Link, H. (2012a). Translanguaging and transnational literacies in multilingual classrooms: a biliteracy lens. International Journal of Bilingual Education and Bilingualism, 15(3), 261-278. https://doi.org/10.1080/13670050.2012.658016.

[25] Hornberger, N. H., \& Link, H. (2012b). Translanguaging in Today's Classrooms: A Biliteracy Lens. Theory Into Practice, 51(4), 239-247. https://doi.org/10.1080/00405841.2012.726051.

[26] Hu, R., \& Commeyras, M. (2008). A case study: Emergent biliteracy in English and Chinese of a 5-year-old chinese child with wordless picture books. Reading Psychology, 29(1), 1-30. https://doi.org/10.1080/02702710701260581.

[27] Jared, D., Cormier, P., Levy, B. A., \& Wade-Woolley, L. (2011). Early Predictors of Biliteracy Development in Children in French Immersion: A 4-Year Longitudinal Study. Journal of Educational Psychology, 103(1), 119-139. https://doi.org/10.1037/a0021284.

[28] Kang, J. Y. (2012). Bilingual PA and its influence on biliteracy for Korean English as a foreign language learners. Reading and Writing, 25(6), 1307-1326. https://doi.org/10.1007/s11145-011-9319-6.

[29] Kwon, H. J., \& Schallert, D. L. (2016). Understanding translanguaging practices through a biliteracy continua framework: Adult biliterates reading academic texts in their two languages. Bilingual Research Journal, 39(2), 138-151. https://doi.org/10.1080/15235882.2016.1167139.

[30] Lindholm-Leary, K. (2014). Bilingual and biliteracy skills in young Spanish-speaking low-SES children: Impact of instructional language and primary language proficiency. International Journal of Bilingual Education and Bilingualism, 17(2), 144-159. https://doi.org/10.1080/13670050.2013.866625.

[31] Lü, C. (2017). The Roles of Pinyin Skill in English-Chinese Biliteracy Learning: Evidence From Chinese Immersion Learners. Foreign Language Annals, 50(2), 306-322. https://doi.org/10.1111/flan.12269.

[32] Lucero, A. (2010). Dora's program: A constructively marginalized paraeducator and her developmental biliteracy program. Anthropology and Education Quarterly, 41(2), 126-143. https://doi.org/10.1111/j.1548-1492.2010.01074.x.

[33] Medina, C., Jo, S., Bobmztjt, U. I. F., Ipx, T., Tuvefout, U. I. F., Bsf, S., Npwfnfout, U. (2010). Translocal Discourses and Cultural Flows in Literature Discussions, 45(1), 40-60.

[34] Mein, E. (2012). Biliteracy in context: the use of L1/L2 genre knowledge in graduate studies. International Journal of Bilingual Education and Bilingualism, 15(6), 653-667. https://doi.org/10.1080/13670050.2012.699946.

[35] Menard-Warwick, J. (2007). Biliteracy and schooling in an extended-family Nicaraguan immigrant household: The sociohistorical construction of parental involvement. Anthropology \& Education Quarterly, 38(2), 119-137. https://doi.org/10.1525/aeq.2007.38.2.119.119.

[36] Miles, M. B., \& Huberman, M. A. (2009). Qualitative data analysis: An expanded sourcebook, Thousand Oaks: SAGE Publ.

[37] Nakamura, P. R., Koda, K., \& Joshi, R. M. (2014). Biliteracy acquisition in Kannada and English: A developmental study. Writing Systems Research, 6(1), 132-147. https://doi.org/10.1080/17586801.2013.855620.

[38] Ngan, H. Y. W. (2009). Developing biliteracy through studying the bilingual representation phenomenon in translation texts. Babel, 55(1), 40-57. https://doi.org/10.1075/babel.55.1.03nga.

[39] Obied, V. M. (2010). Can one - parent families or divorced families produce two - language children? An investigation into how Portuguese-English bilingual children acquire biliteracy within diverse family structures. Pedagogy, Culture \& Society, 18(2), 227-243. https://doi.org/10.1080/14681366.2010.488047.

[40] Proctor, C. P., \& Silverman, R. D. (2011). Confounds in Assessing the Associations Between Biliteracy and English Language Proficiency. Educational Researcher, 40(2), 62-64. https://doi.org/10.3102/0013189X11403138.

[41] Pu, C. (2010). The Influence of Heritage Language and Public Schools on Chinese American Children's Biliteracy Development. Bilingual Research Journal, 33(2), 150-172. https://doi.org/10.1080/15235882.2010.503459.

[42] Rauch, D. P., Naumann, J., \& Jude, N. (2012). Metalinguistic awareness mediates effects of full biliteracy on third-language reading proficiency in Turkish-German bilinguals. International Journal of Bilingualism, 16(4), 402-418. https://doi.org/10.1177/1367006911425819.

[43] Reddy, P. P., \& Koda, K. (2013). Orthographic constraints on phonological awareness in biliteracy development. Writing Systems Research, 5(1), 110-130. https://doi.org/10.1080/17586801.2012.748639.

[44] Reyes, I., \& Azuara, P. (2008). Emergent biliteracy in young Mexican immigrant children. Reading Research Quarterly, 43(4), 374-398. https://doi.org/10.1598/RRQ.43.4.4.

[45] Reyes, I., Kenner, C., Moll, L. C., Orellana, M. F., Reyes, I., \& Moll, L. C. (2012). Biliteracy Among Children and Youths. Reading Research Quarterly, 47(3), $\quad 307-327 . \quad$ Retrieved http://www.jstor.org.ez.unisabana.edu.co/stable/pdf/43497522.pdf.

[46] Ro, Y. E., \& Cheatham, G. A. (2009). Biliteracy and Bilingual Development in a Second-Generation Korean Child: A Case Study. Journal of Research in Childhood Education, 23(3), 290-308. https://doi.org/10.1080/02568540909594662.

[47] Rodriguez-Valls, F., Montoya, M., \& Valenzuela, P. (2014). Biliteracy Summer Schools: Breaking the Cycle of Monolingualism in Migrant Families. Childhood Education, 90(2), 107-115. https://doi.org/10.1080/00094056.2014.894813.

[48] Rodríguez, J. L., \& Cadiero-Kaplan, K. (2008). Bilingualism \& biliteracy: Issues of equity, access, \& social justice for English language learners: Introduction to this special issue. Equity \& Excellence in Education, 41(3), $275-278$. https://doi.org/10.1080/10665680802179139. 
[49] Rubinstein-Ávila, E., Sox, A. A., Kaplan, S., \& McGraw, R. (2015). Does Biliteracy + Mathematical Discourse = Binumerate Development? Language Use in a Middle School Dual-Language Mathematics Classroom. Urban Education, 50(8), $899-937$. https://doi.org/10.1177/0042085914536997.

[50] Sandra I. Musanti. (2015). "Porque se los Dos Idiomas." Biliteracy Beliefs and Bilingual Preservice Teacher Identity, 24. https://doi.org/10.1108/S1479-3687201524.

[51] Smith, P. H., \& Murillo, L. A. (2013). Repositioning biliteracy as capital for learning: lessons from teacher preparation at the US-Mexico border. International Journal of Qualitative Studies in Education, 26(3), $301-323$. https://doi.org/10.1080/09518398.2012.762473.

[52] Soltero-González, L., Sparrow, W., Butvilofsky, S., Escamilla, K., \& Hopewell, S. (2016). Effects of a Paired Literacy Program on Emerging Bilingual Children's Biliteracy Outcomes in Third Grade. Journal of Literacy Research: JLR, 48(1), 80. https://doi.org/10.1177/1086296X16653842.

[53] Soto, M. E. (2012). Guiding biliteracy development: Appropriating cross-linguistic and conceptual knowledge to sustain second-language reading comprehension. Bilingual Research Journal, 35(November 2014), $179-196$. https://doi.org/10.1080/15235882.2012.703638.

[54] Toloa, M., McNaughton, S., \& Lai, M. (2009). Biliteracy and language development in Samoan bilingual classrooms: the effects of increasing English reading comprehension. International Journal of Bilingual Education and Bilingualism, 12(5), 513-531. https://doi.org/10.1080/13670050802366465.

[55] Walt, C., \& Dornbrack, J. (2011). Academic biliteracy in South African higher education: strategies and practices of successful students. Language, Culture and Curriculum, 24(1), 89-104. https://doi.org/10.1080/07908318.2011.554985.

[56] Wang, M., Ko, I. Y., \& Choi, J. (2009). The importance of morphological awareness in Korean-English biliteracy acquisition. Contemporary Educational Psychology, 34(2), 132-142. https://doi.org/10.1016/j.cedpsych.2008.12.002.

[57] Wang, M., Yang, C., \& Cheng, C. (2009). The contributions of phonology, orthography, and morphology in Chinese-English biliteracy acquisition. Applied Psycholinguistics, 30(2), 291. https://doi.org/10.1017/S0142716409090122.

[58] Worthy, J., Nuñez, I., \& Espinoza, K. (2016). "Wow, I get to choose now!” Bilingualism and biliteracy development from childhood to young adulthood. Bilingual Research Journal, 39(1), 20-34. https://doi.org/10.1080/15235882.2016.1139518.

[59] Yeung, S. S., \& Ganotice, F. A. (2014). The Role of Phonological Awareness in Biliteracy Acquisition Among Hong Kong Chinese Kindergarteners Who Learn English-as-a-Second Language (ESL). Asia-Pacific Education Researcher, 23(3), 333343. https://doi.org/10.1007/s40299-013-0108-7.

[60] Zhang, D., \& Koda, K. (2014). Awareness of derivation and compounding in Chinese-English biliteracy acquisition. International Journal of Bilingual Education and Bilingualism, 17(1), 55-73. https://doi.org/10.1080/13670050.2012.736949.

[61] Zhang, D., Koda, K., \& Sun, X. (2014). Morphological awareness in biliteracy acquisition: A study of young Chinese EFL readers. International Journal of Bilingualism, 18(6), 570-585. https://doi.org/10.1177/1367006912450953.

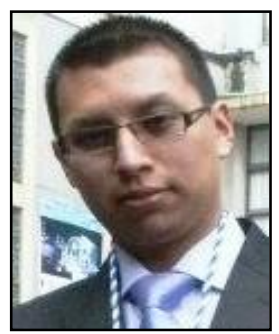

John J. Ducuara was born on August 7, 1988, in Bogotá, Colombia. He obtained his degree in languages, English, French and Spanish at Salle University, Bogotá, Colombia, 2012. He is developing his master's degree in educational computing at Sabana University and his research focus on educational technology and biliteracy.

He has work as English teacher in several institutions, such as private schools, as a high school English and literature teacher. In addition, He has work with kids in a cultural center. The current job is as English teacher at San Bartolomé la Merced, he has been working there for three years in preschool section.

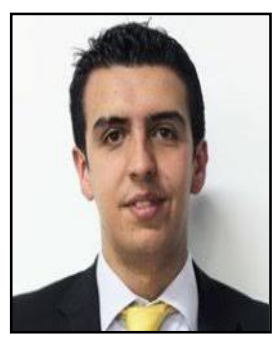

Hugo A. Rozo was born on September 6, 1985, in Bogotá, Colombia. He obtained his degree in Information Systems and Documentation at Salle University, Bogotá, Colombia, 2012. He then obtained his master's degree in educational computing, at Sabana University. Chia, Colombia, 2015. From his undergraduate to master's degree, his action field has been the social sciences. Finally, he is developing his Doctorate in Education studies at Sabana University and his research focus on educational technology.

He has been working for four years as a professor and researcher at Sabana University, in Chia, Colombia, specifically at the Technology Center for the Academy, where he directs undergraduate and postgraduate classes. He leads a research project related to educational practices of the 21 st century and in his PhD he is researching the theories of experiential learning with technology. Among the activities carried out at the University, he is the coordinator of a Seedbed of Research in Digital Competence. He has published articles and book chapters related to the field of research.

Hennig, C., Rozo, H., \& Segovia, Y. (2016). Training professors in ICT: Personal Learning Environments. A grounded theory research study. Journal of e-Learning and Knowledge Society, 12( 1).

Rozo, H. (2016). Desarrollo de la competencia digital en estudiantes universitarios: un estudio de caso. Opción, 32(10).

Ramírez, M., Celis, M., Rodríguez, L., \& Rozo, H. (2017). El grafiti como artefacto comunicador de las ciudades: Una revisión de literatura. Encuentros, 15 (1), 77-89. doi:http://dx.doi.org/10.15665/re.v15i1.812

Prof. Rozo, belongs as a researcher to the research group Proventus, classified by Colciencias in A category. He is a researcher of the Observatory of Technology and Educational Innovation, belongs to the academic committee of the Ibero-American Network of Researchers in Innovation and Educational Technology RIIITED, and he is organizer of the International Congress of Technology and Educational Innovation (CITIE). Last year, he won an award from the Ministry of Culture of Colombia, for designing an innovative service with the use of ICT. 